\title{
Thalidomide Embryopathy Syndrome
}

National Cancer Institute

\section{Source}

National Cancer Institute. Thalidomide Embryopathy Syndrome. NCI Thesaurus. Code C99082.

Fetal embryopathy associated with maternal thalidomide use during pregnancy characterized by phocomelia of one or all limbs, other limb defects such as thumb abnormalities, and other structural anomalies that may include facial hemangioma, esophageal and duodenal atresia, tetralogy of Fallot, renal agenesis, and anomalies of the external ear. Long term complications may include Moebius syndrome or autism. 